\title{
Aplicação de fungicidas na soja baseada na detecção de uredósporos de Phakopsora pachyrhizi
}

\author{
Fungicide application on soybean plants based \\ on the detection of Phakopsora pachyrhizi uredospores
}

\author{
Valdir Lourenço Jr. ${ }^{1 *}$, Marcelo Gonçalves Balan², Seiji Igarashi ${ }^{3}$

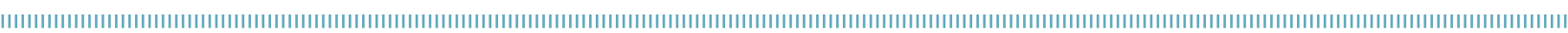

\begin{abstract}
RESUMO: Para estabelecer o momento adequado da aplicação de fungicidas no manejo da ferrugem asiática da soja (FAS), avaliou-se a época da pulverização dos fungicidas epoxiconazole e piraclostrobina (FEP) com base na detecção de uredósporos de Phakopsora pachyrhizi (PP) em condiçóes de campo na área experimental da Faculdade Integrado de Campo Mourão, no Paraná, na safra verão de 2009/2010. O delineamento experimental foi realizado em blocos ao acaso, com sete tratamentos e quatro repetiçóes, sendo: 1) aplicação do FEP com umidade acima de $80 \%$; 2-5) aplicação do FEP 1-2, 6-7, 11-12 e 18-20 dias após a detecção dos primeiros esporos de PP, respectivamente; 6) aplicação do FEP após a detecção dos primeiros sintomas da FAS; 7) aplicação do FEP no estádio R1. A testemunha foi composta por plantas não tratadas com FEP. Houve redução da severidade da FAS em todos os tratamentos. Os valores da área abaixo da curva de progresso da FAS (AACPFA), taxa de progresso da doença $(r)$ e severidade máxima $\left(Y_{\max }\right)$ na testemunha foram de 520,$31 ; 0,06$ e $45,65 \%$, respectivamente. Foram detectados os menores valores de AACPFA $(39,73)$, $r(0,02)$ e $Y_{\max }(3,91 \%)$ no tratamento 1 . No entanto, o maior número de pulverizaçóes do FEP foi realizado neste tratamento, com quatro aplicaçôes. No tratamento 4 , houve duas aplicaçóes. Registrou-se a menor produtividade na testemunha $\left(2085 \mathrm{~kg}\right.$. ha- $\left.{ }^{-1}\right)$. A maior produtividade foi obtida nos tratamentos 1, 2, 3, 4, 6 e 7 , acima de $3000 \mathrm{~kg} \mathrm{ha}^{-1}$. Além disso, registrou-se o menor valor da massa de mil grấos na testemunha. Os maiores valores foram obtidos nos tratamentos 1, 2, 3 e 6 . Portanto, a época de aplicação de fungicida baseada na detecçáo de uredósporos de PP é eficiente no manejo da FAS.
\end{abstract}

PALAVRAS-CHAVE: epidemiologia; controle químico; ferrugem asiática da soja; Glycines max.

\begin{abstract}
In order to establish the adequate timing of fungicide application in the management of Asian soybean rust (ASR), the spraying of epoxiconazol and pyraclostrobin fungicide (EPF) was evaluated based on the detection of Phakopsora pachyrhizi (PP) uredospores in field conditions at the research farm of Faculdade Integrado de Campo Mourão, in the state of Paraná, in the crop season of 2009/2010. The experimental design was performed in randomized complete blocks with four replications composed by: 1) EPF application with humidity higher than $80 \%$; 2-5) EPF application 1-2, 6-7, 11-12, and 18-20 days after the first detection of PP spores, respectively; 6) EPF application after the first detection of ASR symptoms; 7) EPF application in the R1 stage. Control was constituted by plants not treated with EPF. There was reduced ASR severity in all treatments. The values of the area under ASR progress curve (AUASRPC), rate of disease progress $(r)$, and maximum severity $\left(Y_{\max }\right)$ in control were 520.31, 0.06, and 45.65\%, respectively. The lowest values of AUASRPC (39.73), $r$ (0.02), and $Y_{\max }$ $(3.91 \%)$ were found in treatment 1 . Nevertheless, the higher number of EPF spraying was carried out in this treatment with four applications. On the other hand, there were two applications in treatment 4. The lowest yield was recorded in control $\left(2085 \mathrm{~kg}\right.$. ha $\left.{ }^{-1}\right)$. The highest yield was obtained in treatments 1, 2, 3, 4, 6, and 7, being higher than $3000 \mathrm{~kg} / \mathrm{ha}$. Furthermore, the lowest value of the thousand grain weight was estimated in control. The highest values were estimated in treatments 1, 2, 3, and 6 . Therefore, the timing of fungicide application based on the detection of PP uredospores is efficient in the ASR management.
\end{abstract}

KEYWORDS: epidemiology; chemical control; asian soybean rust; Glycines max. 


\section{INTRODUÇÃO}

Atualmente, o Paraná é um dos maiores estados produtores de soja no Brasil, com área cultivada e produção estimadas em aproximadamente 4 mil hectares e 15 milhões de toneladas, respectivamente (ConAB, 2011). Apesar de a produtividade de soja no Paraná estar acima da média nacional (3360 kg ha $\left.{ }^{-1}\right)$, a ferrugem asiática, causada por Phakopsora pachyrhizi Sydow, causa perdas elevadas de produçáo, podendo variar de 10 a 90\% (Hikishima et al., 2010; Yorinori et al., 2005).

A doença é favorecida por temperaturas ao redor de $18-26^{\circ} \mathrm{C}$ e períodos de molhamento foliar superiores a 15 horas (ALVES et al., 2007). Inicialmente, o fungo causa lesões pequenas, de cor castanha a marrom escura, próximas às nervuras das folhas (Goellner et al., 2010). Depois de cinco a oito dias, ocorre o aumento das lesóes e o amarelecimento do tecido foliar com o desenvolvimento de pústulas, principalmente na face abaxial das folhas, além da liberação de uredósporos pelas urédias (Goellner et al., 2010). Sob ataque severo do fungo ocorre a desfolha da planta, o que causa redução no número de vagens e grãos (Hirano et al., 2010).

Como a maioria dos cultivares de soja é suscetível a P. pachyrhizi, o controle químico é o principal método utilizado para o manejo da doença (Godoy et al., 2009; Goulart et al., 2011; MADALOSso et al., 2010). Os principais fungicidas utilizados no manejo da ferrugem asiática pertencem ao grupo dos triazóis e estrobilurinas (Godoy; CANTERI, 2004; GoULART et al., 2011). De forma geral, a aplicação desses fungicidas é feita no aparecimento dos primeiros sintomas da doença, ou preventivamente, no início do florescimento das plantas (GARDiano et al., 2010; Godoy et al., 2009). No entanto, a aplicação de fungicidas é desnecessária quando as condiçōes ambientais são desfavoráveis ao desenvolvimento da doença e quando não há liberação e dispersão de uredósporos na regiáo produtora (Del Ponte; Esker, 2008; Gardiano et al., 2010; Godoy et al., 2009).

O uredósporo é o principal inóculo de P. pachyrhizi que pode ser disperso a centenas de quilômetros (BARNes et al., 2009). Dessa forma, métodos para monitorar o início da liberação e a dispersão de esporos nas áreas produtoras são desejáveis para prever surtos epidêmicos conforme as condiçóes ambientais, e definir o momento adequado para a aplicação de fungicidas (Del Ponte; Esker, 2008; Gardiano et al., 2010). Estudos semelhantes foram conduzidos para definir a época de aplicação de fungicidas com base na detecção de esporos de outros patógenos importantes, como Peronospora tabacina (RACCA et al., 2007), Alternaria solani (Escuredo et al., 2011) e Venturia inaequalis (Bowen et al., 2011).

No Brasil, conduziu-se um estudo para determinar o início da aplicação de fungicidas de ação preventiva, com base na detecção de esporos de $P$. pachyrhizi associada às condições ambientais no manejo da ferrugem asiática em Londrina (PR) (GARDiAno et al., 2010). Houve redução na porcentagem da área foliar infectada e desfolha nos tratamentos com a aplicação de fungicidas 1,7 e 14 dias após a detecção dos primeiros uredósporos comparados com o método de monitoramento convencional (GARDIANO et al., 2010). Como o experimento foi conduzido apenas em um local, é necessário validar a eficácia desse método de monitoramento em outras regiōes produtoras com condiçōes edafoclimáticas distintas, para assim estabelecer o momento adequado da aplicação de fungicidas.

Como o principal núcleo regional produtor de soja no Paraná é Campo Mourão (HuBNer, 2010), é importante implementar esse método de monitoramento de uredósporos nesta região para otimizar o manejo da ferrugem asiática e reduzir a contaminação ambiental, assim como o risco de seleçấo de isolados do fungo resistentes a fungicidas. Dessa forma, o objetivo deste estudo foi avaliar a época de aplicação de fungicida de ação preventiva com base na detecção de uredósporos de P. pachyrhizi em condiçōes de campo no município de Campo Mourão (PR).

\section{MATERIAL E MÉTODOS}

O experimento foi conduzido durante a safra 2009/2010, no campus da Faculdade Integrado de Campo Mourão (PR). O solo da região é classificado como latossolo vermelho distroférrico (Embrapa, 2005), A semeadura da soja foi realizada no dia 11 de novembro de 2009, conduzida no sistema de plantio direto sobre palhada de aveia preta (Avena sativa). Utilizou-se o cultivar CD 214 RR no espaçamento de 0,45 m entrelinhas e 12 plantas por metro linear ${ }^{-1}$. A condução da cultura foi realizada conforme as recomendaçốes de SEDIYAMa (2009).

O delineamento experimental utilizado foi o de blocos ao acaso, com oito tratamentos e quatro repetiçóes. Cada parcela foi constituída por quatro linhas de $5,5 \mathrm{~m}$ de comprimento. Os seguintes tratamentos foram avaliados: 1 ) aplicação do fungicida com umidade acima de $80 \%$; 2-5) aplicação do fungicida 1-2, 6-7, 11-12 e 18-20 dias após a detecção dos primeiros esporos de $P$. pachyrhizi, respectivamente; 6) aplicação do fungicida após a detecção dos primeiros sintomas da ferrugem asiática; 7) aplicação do fungicida no estádio R1. O fungicida foi reaplicado a cada 15-18 dias em todos os tratamentos. A testemunha foi composta por plantas sem tratamento com fungicida.

O fungicida piraclostrobina + epoxiconazole foi utilizado nos tratamentos nas doses de 109,8 g.ha ${ }^{-1}$ e 91,5 g.ha ${ }^{-1}$, respectivamente. Para a aplicação desse fungicida, utilizou-se um pulverizador costal de precisão pressurizado com $\mathrm{O}_{2}$, com pressão constante de $207 \mathrm{kPa}$, barra de três metros com seis pontas do tipo leque de uso ampliado (XR 110.02) e calibrado para uma taxa de aplicação de 200 L.ha ${ }^{-1}$. O espaçamento entre pontas foi de $0,5 \mathrm{~m}$, com a altura de aplicaçấo de $0,5 \mathrm{~m}$ em relação ao dossel da cultura. 
No centro da área experimental foi instalado um coletor de esporos "SIGA" para o monitoramento de uredósporos de $P$. pachyrhizi em lâminas de microscopia, com fita adesiva de dupla face (GARDiano et al., 2010). As lâminas foram retiradas do coletor de esporos em intervalos regulares de dois e cinco dias, e foram levadas ao Laboratório de Fitopatologia e Microbiologia Agrícola da Faculdade Integrado de Campo Mourão para análise e detecção dos uredósporos do fungo. Utilizou-se um microscópio para visualizar e identificar os esporos do fungo em área delimitada por uma lamínula com a dimensão de $2 \times 2 \mathrm{~cm}$.

As avaliaçóes da severidade da doença foram realizadas semanalmente após a detecção dos primeiros sintomas nas plantas, por meio de uma escala diagramática (Godor et al., 2006). Avaliou-se uma folha do terço inferior, médio e superior de dez plantas ao acaso nas duas linhas centrais de cada parcela até a maturação dos grãos.

A colheita foi realizada no dia 16 de março de 2010, manualmente, coletando-se dez plantas aleatoriamente das duas fileiras centrais para determinar a produtividade e a massa de mil grãos de cada parcela. A umidade dos grãos foi corrigida para $13 \%$.

Estimou-se a área abaixo da curva do progresso da ferrugem asiática (AACPFA) a partir de valores da severidade. O modelo das curvas de progresso e os valores da taxa de progresso da doença $(r$ ) foram analisados (CAmpbelL; Madden, 1990). Os valores de severidade no final do ciclo da cultura $\left(Y_{\max }\right)$, a massa de mil grãos e a produtividade $\left(\mathrm{kg} \cdot \mathrm{ha}^{-1}\right)$ foram submetidos à análise de variância e as médias foram comparadas pelo teste de diferença mínima significativa de Fisher, a 5\% de probabilidade. As análises estatísticas foram conduzidas no programa SAS (SAS Institute, Cary, NC, versão 9.1).

\section{RESULTADOS E DISCUSSÃO}

As condiçóes ambientais foram favoráveis ao desenvolvimento da ferrugem asiática durante toda a condução do experimento (Fig. 1). Os valores médios de temperatura e umidade relativa foram de aproximadamente $24^{\circ} \mathrm{C}$ e $80 \%$, respectivamente. Além disso, houve longos períodos de precipitação durante o ciclo de cultivo da soja, principalmente durante o estádio R1, que é o mais suscetível à ferrugem asiática. Nas regiốes produtoras em que a temperatura não é um fator limitante à ocorrência da ferrugem asiática, a severidade da doença no estádio de florescimento pode ser superior a $70 \%$ quando o volume de precipitação estiver ao redor de $250 \mathrm{a} 450 \mathrm{~mm}$ no período de 14 a 24 dias (Del Ponte et al., 2006). Neste estudo, o volume total de precipitação do início do florescimento até a última data de avaliação da ferrugem asiática foi de aproximadamente $400 \mathrm{~mm}$ (Fig. 1).
Apesar das condiçôes ambientais favoráveis à ocorrência da ferrugem asiática, houve redução da severidade da doença em todos os tratamentos (Fig. 2). Os maiores valores de AACPFA, $r$ e $Y_{\text {max }}$ foram observados na testemunha (Tabelas 1 e 2). No entanto, não houve diferenças nos valores de $r$ entre a testemunha e o tratamento 5 (Tabelas 1 e 2). Foram detectados os menores valores de AACPFA, $r$ e $Y_{\max }$ no tratamento 1. O modelo de Gompertz foi o mais adequado para a descrição dos dados de progresso da ferrugem asiática.

O maior número de pulverizaçóes de fungicida foi realizado no tratamento 1 (Tabela 1). A primeira pulverização de fungicida nesse tratamento foi realizada no dia 31/12/2009, no início do estádio R1, o que coincidiu com o momento de aplicaçấo no tratamento 7 , realizado dois dias depois. A aplicaçáo de fungicida nas parcelas do tratamento 6 foram feitas no dia $7 / 1 / 2010$, após a constatação dos primeiros sintomas da doença. Como os primeiros uredósporos de $P$. pachyrhizi foram detectados a partir do dia 16/01/2010, realizou-se a aplicação do fungicida nos tratamentos 3 e 4, no estádio R3. Posteriormente, a primeira aplicação do fungicida no tratamento 5 foi realizada no dia 28/01/2010 (estádio R4). Dessa forma, o menor número de pulverizações foi realizado nos tratamentos 4 e 5 (Tabela 1 ).

Resultados similares foram obtidos em outro estudo conduzido em Londrina (GARDiano et al., 2010). Houve redução da porcentagem da área foliar infectada e da desfolha nos tratamentos com a aplicação de fungicidas quando a umidade estava acima de $80 \%$, e 1,7 e 14 dias após a detecçáo de uredósporos de P. pachyrhizi. O menor número de pulverizaçôes foi realizado no tratamento com a aplicação de fungicidas 14 dias depois da detecção de esporos do fungo (Gardiano et al., 2010).

Neste estudo, os primeiro sintomas da ferrugem asiática foram observados antes da detecçáo dos uredósporos do fungo. Portanto, é necessário instalar mais de um coletor de esporos na área de cultivo para melhorar a eficiência da detecção de uredósporos. Como o número de uredósporos estava baixo, um único coletor não foi suficiente para o monitoramento. Outro fato interessante é que, apesar das condiçôes ambientais terem sido favoráveis à ferrugem asiática desde a emergência da cultura, os primeiros sintomas e esporos do fungo foram observados apenas no estádio de florescimento. Uma hipótese é que o estabelecimento do vazio sanitário desde 2006 esteja contribuindo para a redução do inóculo do patógeno nas áreas produtoras (Godoy et al., 2009).

Além da eficiência no controle da ferrugem asiática, houve maior produtividade de grãos nos tratamentos 1, 2, 3, 4, 6 e 7 (Tabela 1). A menor produtividade foi detectada na testemunha. Com relação à massa de mil grãos, os maiores valores foram obtidos nos tratamentos 1, 2, 3 e 6 (Tabela 1). Na testemunha, registrou-se o menor valor da massa de mil grãos (Tabela 1). 


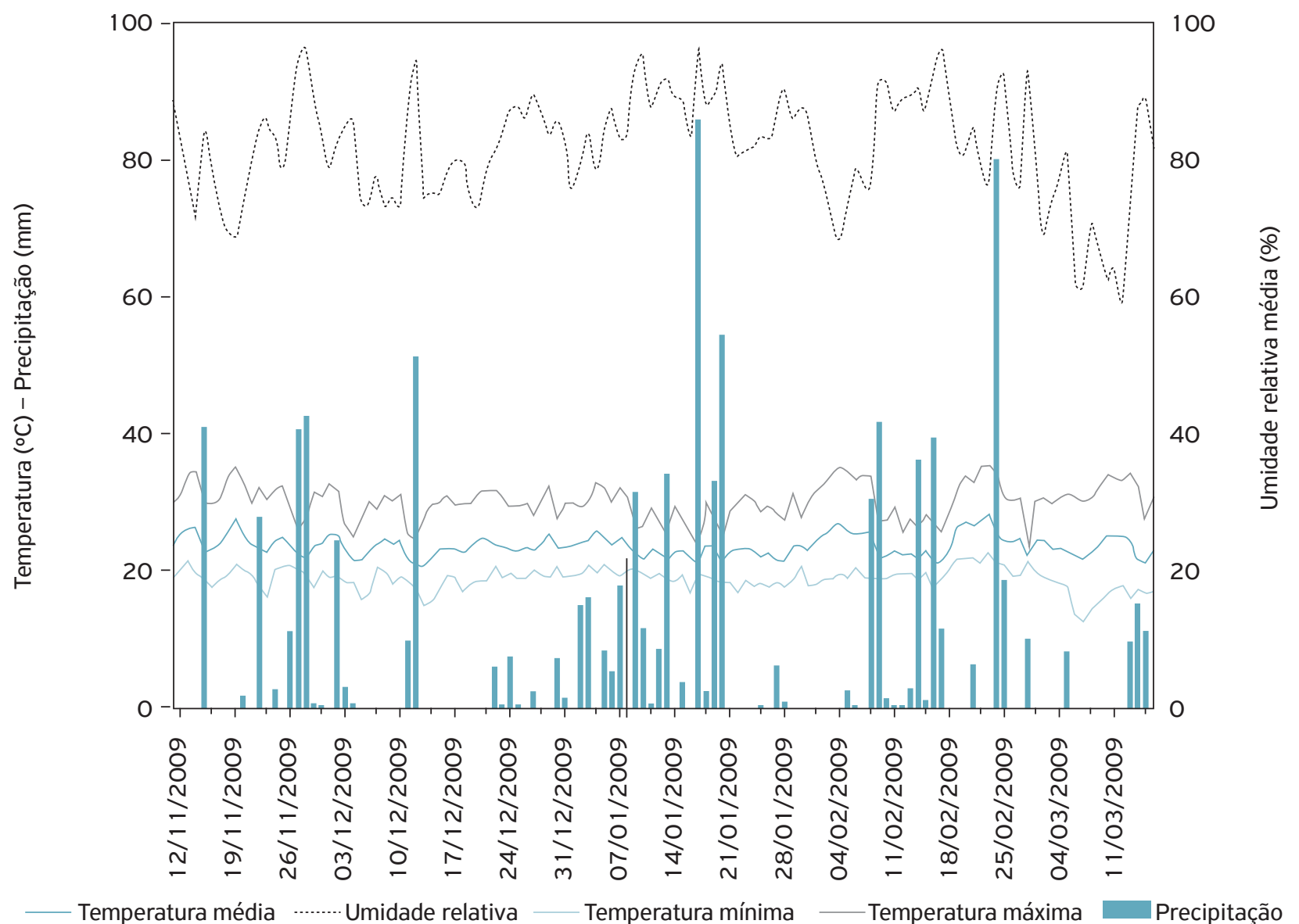

Figura 1. Temperatura do ar (máxima, mínima e média), precipitação pluviométrica $(\mathrm{mm})$ e umidade relativa do ar (\%) registradas em Campo Mourão (PR) na safra verão de 2009/2010.

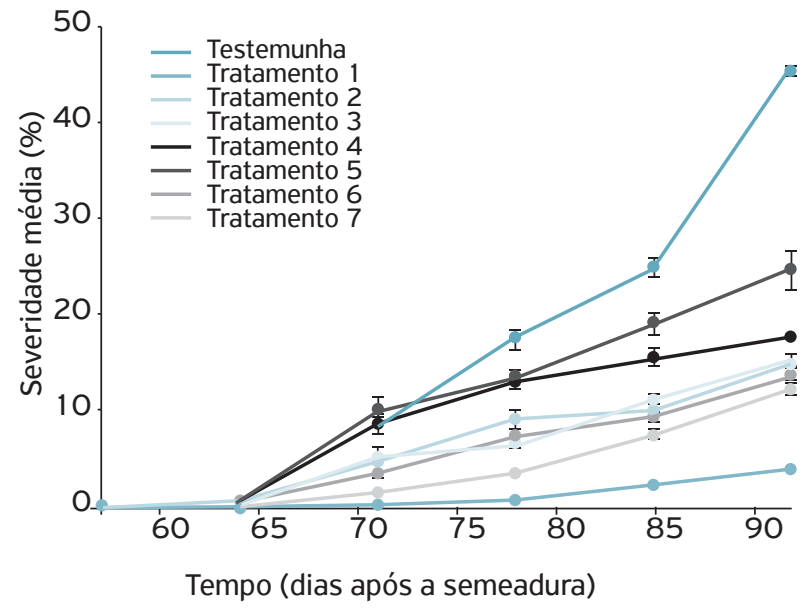

Figura 2. Curva de progresso da ferrugem asiática da soja na testemunha e nos tratamentos $1,2,3,4,5,6$ e 7 (descritos na Tabela 1). Barras representam o erro padrão da média.
Similarmente, em outro estudo o maior rendimento de grãos foi obtido nos tratamentos com a época de aplicação de fungicidas baseada na detecção dos uredósporos e no monitoramento climático e convencional (GARDIANo et al., 2010).

O tratamento 5 foi o menos efetivo no controle da ferrugem asiática (Tabelas 1 e 2). Como as condiçóes ambientais foram favoráveis à ferrugem asiática principalmente no estádio de florescimento, a aplicação de fungicidas nesse tratamento foi tardia, o que comprometeu o rendimento e a massa de mil grãos. Observou-se em outro estudo que a eficiência de controle e o rendimento de grãos foram menores com a primeira aplicaçáo de fungicida realizada no estádio $\mathrm{R} 4$, em comparação aos tratamentos realizado no estádio R3 (Godoy et al., 2009). Dessa forma, não é recomendado que a primeira aplicação de fungicida seja feita 18 a 20 dias após a detecção de uredósporos de P. pachyrhizi em condiçôes ambientais favoráveis ao desenvolvimento da doença. 
Tabela 1. Valores médios da área abaixo da curva de progresso da ferrugem asiática (AACPFA), da taxa de progresso da doença ( $r$ ), da severidade do final do ciclo da cultura $\left(Y_{\max }\right)$, da produção e da massa de mil grãos de soja.

\begin{tabular}{|c|c|c|c|c|c|c|}
\hline Tratamento ${ }^{1}$ & $\begin{array}{c}\text { Número de } \\
\text { pulverizações }\end{array}$ & AACPFA & $r$ & $Y_{\max }$ & Produção kg ha-1 & Massa de mil grãos \\
\hline 1 & 4 & $39,73 f^{2}$ & 0,02 & $3,91 \mathrm{f}$ & 3933 a & $123 a$ \\
\hline 2 & 3 & $224,00 \mathrm{~d}$ & 0,04 & $14,98 d$ & $3772 \mathrm{a}$ & $116 a b$ \\
\hline 3 & 3 & $217,22 d$ & 0,04 & $14,96 \mathrm{~d}$ & $3585 a b$ & $117 a$ \\
\hline 4 & 2 & $325,40 \mathrm{c}$ & 0,04 & $17,75 \mathrm{c}$ & $3025 a b c$ & $109 b c$ \\
\hline 5 & 2 & $388,24 b$ & 0,05 & $24,54 b$ & $2760 \mathrm{bc}$ & $103 c$ \\
\hline 6 & 3 & $192,80 \mathrm{~d}$ & 0,04 & 13,73 de & $3093 a b$ & $116 a b$ \\
\hline 7 & 3 & $132,95 \mathrm{e}$ & 0,04 & $12,25 \mathrm{e}$ & $3200 a b$ & $117 a$ \\
\hline Testemunha & 0 & $520,31 a$ & 0,06 & $45,65 a$ & $2085 c$ & $93 d$ \\
\hline
\end{tabular}

1: testemunha (plantas não pulverizadas com fungicida). Tratamentos: 1) aplicação de fungicida com umidade relativa acima de $80 \%$;

2-5) aplicação do fungicida $1-2,6-7,11-12$ e $18-20$ dias depois da detecção dos primeiros esporos de $P$. pachyrhizi, respectivamente;

6) aplicação de fungicida após a detecção dos primeiros sintomas da ferrugem; e 7) aplicação de fungicida no estádio R1.

2: médias seguidas de letras iquais não diferem ao nível de $5 \%$ de probabilidade pelo teste de diferença mínima significativa de Fisher.

Tabela 2. Limite inferior e superior do intervalo de confiança a 95\% para a diferença da taxa de progresso da doença ( $r$ ) estimada para cada par de tratamento. Os valores de $r$ foram estimados do modelo de Gompertz utilizado na descrição do progresso da ferrugem asiática.

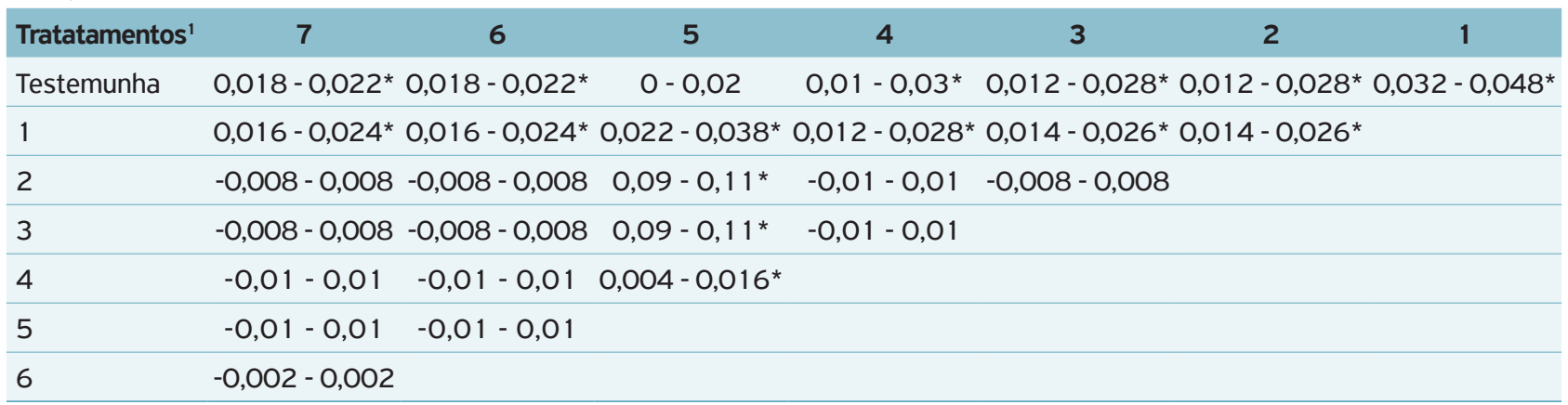

1: tratamentos descritos na tabela 1; *Os valores são similares quando o valor zero é incluído no intervalo.

A partir dos resultados obtidos neste estudo, o tratamento 4 foi um dos mais efetivos na redução dos valores de AACPFA, $r$ e $Y_{\text {max }}$. Além disso, um dos maiores rendimentos e massa de mil grãos foram obtidos nesse tratamento, com o menor número de aplicaçóes de fungicidas. Dessa forma, o monitoramento de uredósporos de P. pachyrhizi para definir o momento da primeira aplicaçâo de fungicidas é recomendado para o manejo da ferrugem asiática. Os resultados obtidos foram similares aos do estudo conduzido em Londrina (Gardiano et al., 2010). O uso desse método reduz a contaminação ambiental e o custo de produção. Estudos associando esse método de monitoramento a outras medidas de controle devem ser conduzidos para promover o manejo integrado da ferrugem asiática da soja.

\section{CONCLUSÕES}

Os tratamentos 1, 2, 3, 4, 6 e 7 foram eficientes na redução dos valores de AACPFA, $r$ e $Y_{\text {max }}$. Além disso, os maiores valores de produtividade e de massa de mil grãos de soja foram obtidos nesses tratamentos. Contudo, houve menor número de aplicaçôes de fungicida no tratamento 4 .

\section{AGRADECIMENTOS}

Ao Instituto Tecnológico SIMEPAR, pelo fornecimento dos dados de temperatura, precipitação e umidade relativa da estação meteorológica de Campo Mourão (PR). 


\section{REFERÊNCIAS}

ALVES, M.C.; POZZA, E.A.; FERREIRA, J.B.; ARAÚJO, D.V.D.; COSTA, J.D.C.D.B.; DEUNER, C.C.; MUNIZ, M.D.F.S.; ZAMBENEDETTI, E.B.; MACHADO, J.D.C. Intensidade da ferrugem asiática (Phakopsora pachyrhizi H. Sydow \& P. Sydow) da soja [Glycine max (L.) Merr.] nas cultivares Conquista, Savana e Suprema sob diferentes temperaturas e períodos de molhamento foliar. Summa Phytopathologica, Botucatu, v.33, p.239-244, 2007.

BARNES, C.W.; SZABO, L.J.; BOWERSOX, V.C. Identifying and quantifying Phakopsora pachyrhizi spores in rain. Phytopathology, St. Paul, v.99, p.328-338, 2009.

BOWEN, J.K.; MESARICH, C.H.; BUS, V.G.M.; BERESFORD, R.M.; PLUMMER, K.M.; TEMPLETON, M.D. Venturia inaequalis: the causal agent of apple scab. Molecular Plant Pathology, Oxford, v.12, p.105-122, 2011.

CAMPBELL, C.L.; MADDEN, L.V. Introduction to plant disease epidemiology. New York: John Wiley \& Sons, 1990. 532p.

CONAB. Acompanhamento de safra brasileira: grãos, primeiro levantamento, outubro 2011. Brasília: Companhia Nacional de Abastecimento, 2011.40p.

DEL PONTE, E.M.; ESKER, P.D. Meteorological factors and Asian soybean rust epidemics - a systems approach and implications for risk assessment. Scientia Agricola, Piracicaba, v.65, p.8897, 2008.

DEL PONTE, E.M.; GODOY, C.V.; LI, X.; YANG, X.B. Predicting severity of Asian soybean rust epidemics with empirical rainfall models. Phytopathology, St. Paul, v.96, p.797-803, 2006.

EMBRAPA. Sistema brasileiro de classificação de solos. Rio de Janeiro: Embrapa Solos, 2005. 412p.

ESCUREDO, O.; SEIJO, M.C.; FERNÁNDEZ-GONZÁLEZ, M.; IGLESIAS, I. Effects of meteorological factors on the levels of Alternaria spores on a potato crop. International Journal of Biometeorology, Berlin, v.55, p.243-252, 2011.

GARDIANO, C.G.; BALAN, M.G.; FALKOSKI FILHO, J.; CAMARGO, L.C.M.D.; OLIVEIRA, G.M.D.; IGARASHI, W.T.; SUDO, L.T.; IGARASHI, S.; SAAB, O.J.G.A.; CANTERI, M.G. Manejo químico da ferrugem asiática da soja, baseado em diferentes métodos de monitoramento. Arquivos do Instituto Biológico, São Paulo, v.77, p.497-504, 2010.

GODOY, C.V.; CANTERI, M.G. Efeitos protetor, curativo e erradicante de fungicidas no controle da ferrugem da soja causada por Phakopsora pachyrhizi, em casa de vegetação. Fitopatologia Brasileira, Lavras, v.29, p.97-101, 2004.
GODOY, C.V.; KOGA, L.; CANTERI, M. Diagrammatic scale for assessment of soybean rust severity. Fitopatologia Brasileira, Lavras, v.31, p.63-68, 2006.

GODOY, C.V.; FLAUSINO, A.M.; SANTOS, L.C.M.; DEL PONTE, E.M. Eficiência do controle da ferrugem asiática da soja em função do momento de aplicação sob condições de epidemia em Londrina, PR. Tropical Plant Pathology, Lavras, v.34, p.56-61, 2009.

GOELLNER, K.; LOEHRER, M.; LANGENBACH, C.; CONRATH, U.; KOCH, E.; SCHAFFRATH, U. Phakopsora pachyrhizi, the causal agent of Asian soybean rust. Molecular Plant Pathology, Oxford, v. 11, p. 169-177, 2010.

GOULART, A.C.P.; FURLAN, S.H.; FUJINO, M.T. Controle integrado da ferrugem asiática da soja (Phakopsora pachyrhizi) com o fungicida fluquinconazole aplicado nas sementes em associação com outros fungicidas pulverizados na parte aérea da cultura. Summa Phytopathologica, Botucatu, v.37, p.113-118, 2011.

HIKISHIMA, M.; CANTERI, M.G.; GODOY, C.V.; KOGA, L.J.; SILVA, A.J.D. Quantificação de danos e relações entre severidade, medidas de refletância e produtividade no patossistema ferrugem asiática da soja. Tropical Plant Pathology, Lavras, v.35, p.96-103, 2010.

HIRANO M.; HIKISHIMA, M.; SILVA, A.; XAVIER, S.; CANTERI, M. Validação de escala diagramática para estimativa de desfolha provocada pela ferrugem asiática em soja. Summa Phytopathologica, Botucatu, v.36, p.248-250, 2010.

HUBNER, O. Soja - safra 2009/2010. Curitiba: Secretaria da Agricultura e do Abastecimento do Paraná, 2010. 10p. Disponível em: <http://www.agricultura.pr.gov.br/arquivos/File/deral/soja_ relato_2009_10.pdf>. Acesso em: 8 nov. 2010.

MADALOSSO, M.G.; DOMINGUES, L.S.; DEBORTOLI, M.P.; LENZ, G.; BALARDIN, R.S. Cultivares, espaçamento entrelinhas e programas de aplicação de fungicidas no controle de Phakopsora pachyrhizi Sydow em soja. Ciência Rural, Santa Maria, v.40, p.2256-2261, 2010.

RACCA, P.; KLEINHENZ, B.; JÖRG, E. Simperota 1/3 - a decision support system for blue mould disease of tobacco. Bulletin OEPP/ EPPO Bulletin, Oxford, v.37, p.368-373, 2007.

SEDIYAMA, T. Tecnologias de produção e usos da soja. Londrina: Mecenas, 2009. 314p.

YORINORI, J.T.; PAIVA, W.M.; FREDERICK, R.D.; COSTAMILAN, L.M.; BERTAGNOLLI, P.F.; HARTMAN, G.E.; GODOY, C.V.; NUNES JR., J. Epidemics of soybean rust (Phakopsora pachyrhizi) in Brazil and Paraguay from 2001 to 2003. Plant Disease, St. Paul, v.89, p.675-677, 2005. 